УДК 378.78.018.43:616.9

\title{
МЕТОДЫ УЛУЧШЕНИЯ ПСИХИЧЕСКОГО ЗДОРОВЬЯ СТУДЕНТОВ В УСЛОВИЯХ ВЫНУЖДЕННОГО ДИСТАНЦИОННОГО ОБУЧЕНИЯ И СОЦИАЛЬНОГО ДИСТАНЦИРОВАНИЯ
}

\author{
Левин Семен Михайлович, \\ levin.sm@asu.tusur.ru
}

Томский государственный университет систем управления и радиоэлектроники, Россия, 634050, г. Томск, пр. Ленина, 40

\begin{abstract}
Левин Семен Михайлович, кандидат юридических наук, $\mathrm{PhD}$, профессор кафедры автоматизированных систем управления факультета систем управления Томского государственного университета систем управления и радиоэлектроники.
\end{abstract}

Актуальность. В условиях пандемии COVID-19 удалённое обучение стало обязательным для многочисленных вузов мира. Массовый переход на дистанционное обучение был беспрецедентен и не имел исторических аналогов. Связанная с этим необходимость изоляции и социального дистанцирования повлияла на образование студенческих коллективов и последующую адаптацию учащихся в новой социальной группе (студенчестве). Студенты высших учебных заведений столкнулись с дополнительными новыми сложностями, которые привели к усилению проблем с психическим здоровьем. На фоне административных ограничений и невозможности создавать или поддерживать традиционные социальные связи, обусловленные характером студенческого социума, среди обучающихся стало характерным проявление тревоги, симптомов депрессии, серьёзных стрессовых состояний и фактов злоупотребления алкоголем. В этой связи возникла необходимость выявить основные симптомы нарушения психического здоровья и их причины, а также методы устранения или минимизации такой негативной симптоматики. Статья также рассматривает формат личного общения между студентами как необходимый фактор для полноценной социализации и формирования личности каждого учащегося вуза. Целью исследования является всестороннее рассмотрение аспектов нарушений психического здоровья студентов с последующим установлением ключевых каналов социальной поддержки - активных лидеров формальных и неформальных студенческих сообществ, а также преподавателей. Результаты работы выражены в конкретных рекомендациях по улучшению психического здоровья учащихся, с адресным указанием социальных связей, через которые их необходимо реализовывать.

Ключевые слова: Психическое здоровье студентов, дистанционное обучение, социальное дистанцирование.

\section{Введение}

2020 год не был годом космических открытий, которые через десятки лет мы будем вспоминать в историях, с гордостью рассказывая о них молодёжи. Останутся лишь воспоминания о том, как никто не мог выйти из дома без маски, как мы не могли обниматься или здороваться за руку с другими, вынужденные по возможности оставаться дома в целях контроля распространения вируса. Если год, в котором пандемия распространилась в нашем мире, уже закончился, то этого нельзя сказать об изменениях как в жизни отдельных людей, так и всего общества в целом. 
Долгие месяцы ограничений, а в некоторых странах - и изоляции, серьёзно повлияли на наш образ повседневного существования. Радикально изменились рабочие места - часть из них опустела полностью, другие пришлось реорганизовать, чтобы функционировать в изменившихся условиях. Социальные контакты перешли в виртуальную плоскость - изменился наш способ общения. Мы начали стараться контактировать с как можно меньшим количеством людей, и даже встреча с другом, с которым не виделись несколько месяцев, стала предполагаемым риском.

Удалённая работа и дистанционное обучение стали рекомендуемыми, а местами обязательными. Но если удалённые работники - это, как правило, уже сформировавшиеся личности, то студенты - это вчерашние школьники, делающие первые самостоятельные шаги.

Обычно поступление в высшее учебное заведение совпадает с началом молодости - периодом высокой активности человека, завершающим формированием личности и закладывающим фундамент специализации [1]. Сам переход от школьной жизни к студенчеству предполагает смену социальных групп. В качестве последней студенчество представляет собой социум с конкретными характеристиками (социальнодемографической, численной, территориальной, половозрастной и пр.), имеющий определённое положение и статус в обществе.

Принадлежность к такой группе длится от четырёх до шести лет. Это период взросления, формирования самосознания [2], появления собственного мировоззрения. Интенсивность перемен, происходящих в это время с человеком, можно сравнить лишь с интенсивностью адаптации новорожденного к окружающему миру, проходящей примерно за то же время, что и присутствие в студенческом социуме. Активное личностное развитие, формирование морально-нравственных норм, самостоятельности и осознанного проявления по своей важности в дальнейшей жизни студента аналогичны умению ребёнка ходить и общаться с окружающими. Несмотря на утрированность приведённой аллегории, значение студенческого периода в жизни молодёжи это нисколько не умаляет.

\section{Этапы и особенности интеграции в студенческом социуме}

Первый год обучения в вузе по праву считается одним из самых проблемных - caмостоятельные шаги сопровождаются неподготовленностью к обучению, адаптацией в новом коллективе, появлением новых навыков и опыта, переоценкой своих возможностей. К середине периода обучения происходит качественный скачок, в результате которого студент начинает более адекватно оценивать свои профессиональные способности, формирует собственный перечень ценностей, мотивация в достижении целей становится более осознанной и структурированной. Завершающий год обучения - ещё одна переломная грань, характеризующаяся фокусировкой на предстоящую профессиональную деятельность, проявлением большей индивидуальности по сравнению с предыдущими годами и самостоятельности, сопровождающимися постепенным отказом от коллективной формы жизни вуза. Другими словами, происходит постепенная подготовка к прощанию со студенчеством и переходу в следующую социальную группу.

Следует отметить, что первоначальные причины выбора того или иного вуза и, как следствие, определённой группы в студенческом социуме неоднородны. Мотивация формируется в период обучения в школе, и срок такого формирования зависит от многих факторов: воспитание в семье, школьное окружение, мнение авторитетных друзей или педагогов, собственные интересы, основанные на самостоятельном познании мира. Исследования показали, что самой весомой причиной являлось точное знание абитури- 
ента, по какой специальности он будет работать по окончании обучения [3]. Далее, с небольшим отрывом, идут причины, которые дифференцируются по группам приоритетов, в зависимости от категории респондентов - студенты, обучающиеся на бюджете, и те, кто выбрал платное образование. Для первых самыми значимыми были: уровень качество обучения, репутация вуза, наличие в нём необходимой для абитуриента специальности. Для вторых - качество обучения, учёба за компанию с друзьями и близость к дому. Надо сказать, что степень осознанности в выборе учебного заведения в возрасте 17-18 лет весьма невысока. Косвенным подтверждением могут служить данные Всероссийского центра изучения общественного мнения (ВЦИОМ), согласно которым $47 \%$ россиян не работают по специальности [4]. Причин у такого показателя несколько, в число которых входят невозможность устроиться или отсутствие работы по специальности, наличие более высокой заработной платы в другой области, поиск и реализация себя в другой области. Причины такого статистического показателя кроются в решениях как достуденческого периода жизни, так и периода, следующего за получением образования в выбранном вузе, вне зависимости от того, кто повлиял на выбор решил сам, посоветовали родители или СМИ.

Процессы личностного развития, формирования этических норм, социализация происходят в группе, одной из отличительных черт которой - сходство участников по характеру деятельности и интересам [5]. В начале учёбы группа перестраивается в коллектив, члены которого связаны общими целями и задачами. Несмотря на то, что не всякий коллектив, даже наиболее состоявшийся, может оказывать эффективное влияние на его участников, он играет существенную роль в развитии и формировании личности каждого из них.

Психологическая опора в лице близких и родных заменяется, для каждого из студентов в разной степени, аналогичной опорой студенческого коллектива. Схожесть той или иной ситуации, в которой находится студент, с обстоятельствами, в которых находятся его однокурсники, может оказать большее успокаивающее действие, чем ласковые утешения родителей. Личное общение между учащимися - значимый фактор, создающий ощущение общности, принадлежности к одному кругу даже в эпоху т. н. «цифровизации», когда существенный фрагмент повседневной жизни и интересов жителей стран, где обеспечен устойчивый доступ в Интернет, перенесен в виртуальное пространство.

\section{Численные характеристики роста количества пользователей Интернета и социальных сетей}

Сегодня учащиеся вузов - молодёжь, которая не может даже представить себе того времени, когда не было Интернета, нельзя было открыть Google и найти любую интересующую информацию. Старый анекдот о воспитательнице детского сада, привязавшей всех детей к одной песочнице с помощью включённого Wi-Fi с ограниченной зоной покрытия - «Куда они разбегутся, он у нас только в пределах песочницы» нашёл реалистичное отражение в повседневности. Ограничения регистрации аккаунта в социальных сетях, например, носят, скорее, условный характер. Во время процедуры регистрации требуется ввести дату своего рождения и намеренная ошибка в двух последних цифрах года делает доступным новому пользователю обширное информационное пространство. Различные факторы, включая отсутствие действующих механизмов ограничения, привели к заметному росту числа пользователей Интернета во всём мире. С 2013 по 2019 г. количество пользователей сети возросло на 83 \% и составило по состоянию на январь 2020 г. 4,54 миллиарда, что соответствует 59 \% населения плане- 
ты [6]. С 2010 по 2016 г. темпы роста проникновения Интернета превысили 900 \%. Безусловно, общие цифры не отражают специфики отдельных регионов. Однако на примере Евросоюза можно увидеть, что уже в 2016 г. почти 80 \% всего населения пользовалась Интернетом. Так, согласно исследованиям Фукса, Ридла, Бок и др., практически 100 \% немецкоязычных подростков пользовались Интернетом ежедневно, более $80 \%$ использовали его в дороге, а более 50 \% считали Интернет «незаменимым» [7]. Данные о российском интернет-пространстве и его обитателях на январь 2020 г. схожи. По материалам отчёта аналитического агентства GfK, проникновение Интернета среди подростков в возрасте 16-19 лет достигло почти 100 \% [8]. Подростки стремятся к расширению круга контактов и регистрируются в социальных сетях из-за отсутствия живого общения в реальном мире. Виртуальные отношения вытесняют реальные, человек постепенно теряет способность поддержания разговора при личном общении с окружающими. Говорит ли это о том, что живой контакт перестал быть объективной необходимостью? Отнюдь. Студенческое кафе с компанией однокурсников, внимательно изучающих содержание своих смартфонов, - вполне привычная картина и уже не вызывает усмешек со стороны. Однако даже такая группа сохраняет признаки таковой, т. к. объединяет единомышленников со схожими методами поведения. Для вчерашних абитуриентов важность оказаться в среде себе подобных высока даже в том случае, когда бОльшая часть общения реализуется цифровым способом. Личный контакт в период обучения, способствующий взрослению и социализации, необходим для студентов в возрасте 17-25 лет в любом случае [9].

Получение профессионального образования для поступающего в вуз - это шаг на пути к прекращению материальной зависимости от родителей и самореализации в интересующей его на тот момент области. Смена социальных групп порождает необходимость в смене активных социальных связей, что на практике выглядит как активное общение со своими сверстниками, выбравшими те же учебное заведение и факультет, основанное на живом контакте.

Более одного миллиарда человек во всём мире столкнулись в 2020 г. с необходимостью полного или частичного перехода на дистанционный режим обучения [10]. Весомая часть этого миллиарда - студенты высших учебных заведений. Пандемия, повлекшая переход к удалённому обучению подавляющего большинства вузов планеты, изменила характер социальных связей сегодняшнего студенчества. При этом некоторые из связей прекратились или не образовались вообще, если говорить о первокурсниках 2020/21 учебного года. Например, университеты Великобритании встретили в сентябре вновь прибывших открытыми кампусами при закрытых аудиториях и классах. Первокурсники начали и продолжают до сих пор учиться удалённо. Таким образом, формирование полноценного коллектива не произошло, личные контакты свелись к минимуму, а многие из существующих коллективов - не сообщества однокурсников, а небольшие группки студентов, проживающих на одном этаже общежития и связанные обязанностью по уборке общей кухни. Почти вся жизнь учащихся стала виртуальной, за исключением утилитарных функций - питание, стирка, личная гигиена. Косвенно об этом свидетельствуют и показатели мировой «цифровизации», а конкретно - число активных пользователей социальных сетей. За этот год оно увеличилось в процентном отношении к населению планеты с 49 до 53,6 \% [6]. Абсолютные значения говорят о том, что на январь 2021 года число пользователей пополнилось примерно на 400 млн человек по сравнению с январём 2020 г. (рис. 1).

Многие российские вузы повторили сценарий британских. Вновь поступившие студенты, учащиеся по месту жительства, поменяли школьный виртуальный класс на 
университетский, так и не попав на территорию вуза, а учащиеся более старших курсов разошлись по домам, чтобы остаться наедине с компьютером. У проживающих в общежитиях основным отличием стала частично сохранившаяся возможность общения. Тем не менее полноценная система социальных связей прекратила своё существование.

\section{Проблемы нарушения психического здоровья}

Ещё до пандемии COVID-19 растущее распространение проблем эмоционального и психического здоровья было в центре внимания общественного здравоохранения ряда стран. Период формирования студента как самостоятельной личности, его адаптации к изменившимся внешним условиям, в которых он существует, смена социальной группы и характера социальных связей естественным образом могут провоцировать эмоциональные и психические расстройства разной степени тяжести, особенно среди проживающих в кампусах (общежитиях). Так, состояние каждого пятого студента соответствовало диагностическим критериям психического расстройства [11], от 30 до 50 \% учащихся сообщали о сильном стрессе, тревоге и симптомах депрессии [12].

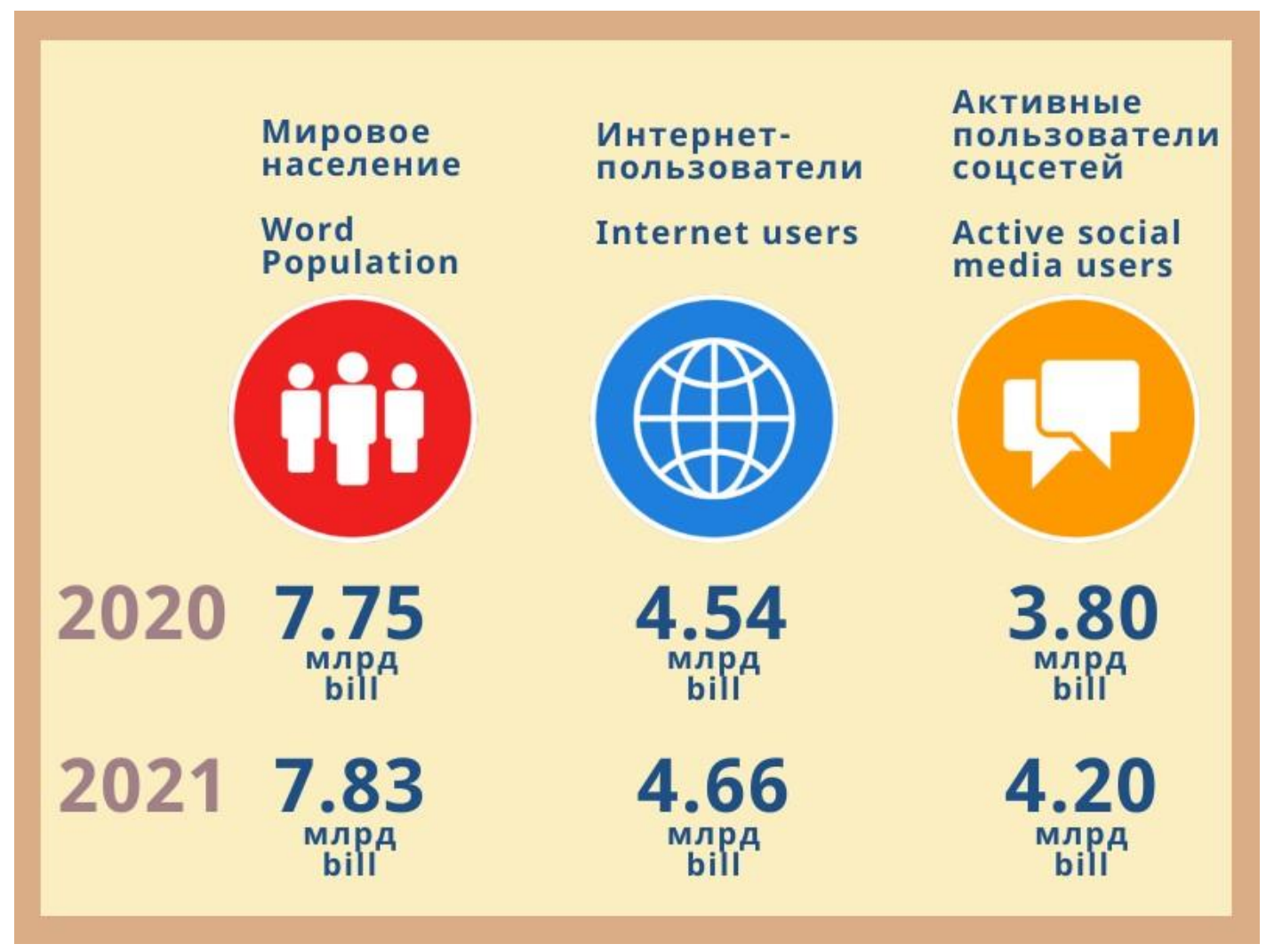

Pис. 1. Основные данные по использованию Интернета и социальных сетей $(2020,2021)$

Fig. 1. Essential headlines for internet, and social media use $(2020,2021)$

Пандемия коронавируса и меры социального дистанцирования вызвали беспрецедентные изменения в процессах обучения. Генеральный директор ЮНЕСКО Одри Азулай отметила, что «глобальные масштабы и скорость нынешнего разрушения образования не имеют себе равных» [13]. Опрос более чем 100000 канадских студентов показал, что у $26 \%$ респондентов занятия были отменены или отложены, $21 \%$ не смогли вовремя завершить курс или пройти ранее запланированную аттестацию, у 35 \% плановое трудоустройство было задержано или отменено [14]. Помимо этого, многие из уча- 
щихся вузов столкнулись с закрытием общежитий и необходимостью переезда, а часть из них попала в ситуацию невозможности физического контакта со своими семьями или университетом в результате наложения запрета на поездки $[13,15]$. Помимо этого, повсеместное закрытие вузов и соблюдение мер по социальному дистанцированию привели к одиночеству и изоляции многих студентов [16-19].

Несмотря на то, что в настоящий момент обширных исследований, посвящённых учащимся вузов в связи с пандемией COVID-19, не так много, согласно перекрёстным данным некоторых исследований, от 20 до $35 \%$ студентов сообщают о тревоге, от 20 до $30 \%$ - о симптомах депрессии, $25 \%$ - о злоупотреблении алкоголем и от 10 до $30 \%$ говорят о серьезном стрессе [20-25]. Также результаты этих исследований показывают, что молодёжь может подвергаться повышенному риску дистресса - невозможности полной адаптации к стрессовым факторам и вызванному ими стрессу [20, 25].

Группа исследователей провела изучение воздействия COVID-19 на психическое здоровье студентов высших учебных заведений и постаралась по-новому взглянуть на то, как и насколько уязвимы студенты для психологического стресса, вызванного COVID-19 [26]. Результаты показали, что 33 \% учащихся сообщили о клинически значимых депрессивных симптомах, 27,3 \% сообщили о тревоге, 9,4 \% - о симптомах ПРЛ (пограничного расстройства личности) и $10,4 \%$ - о симптомах расстройства, связанного со злоупотреблением алкоголем (рис. 2).

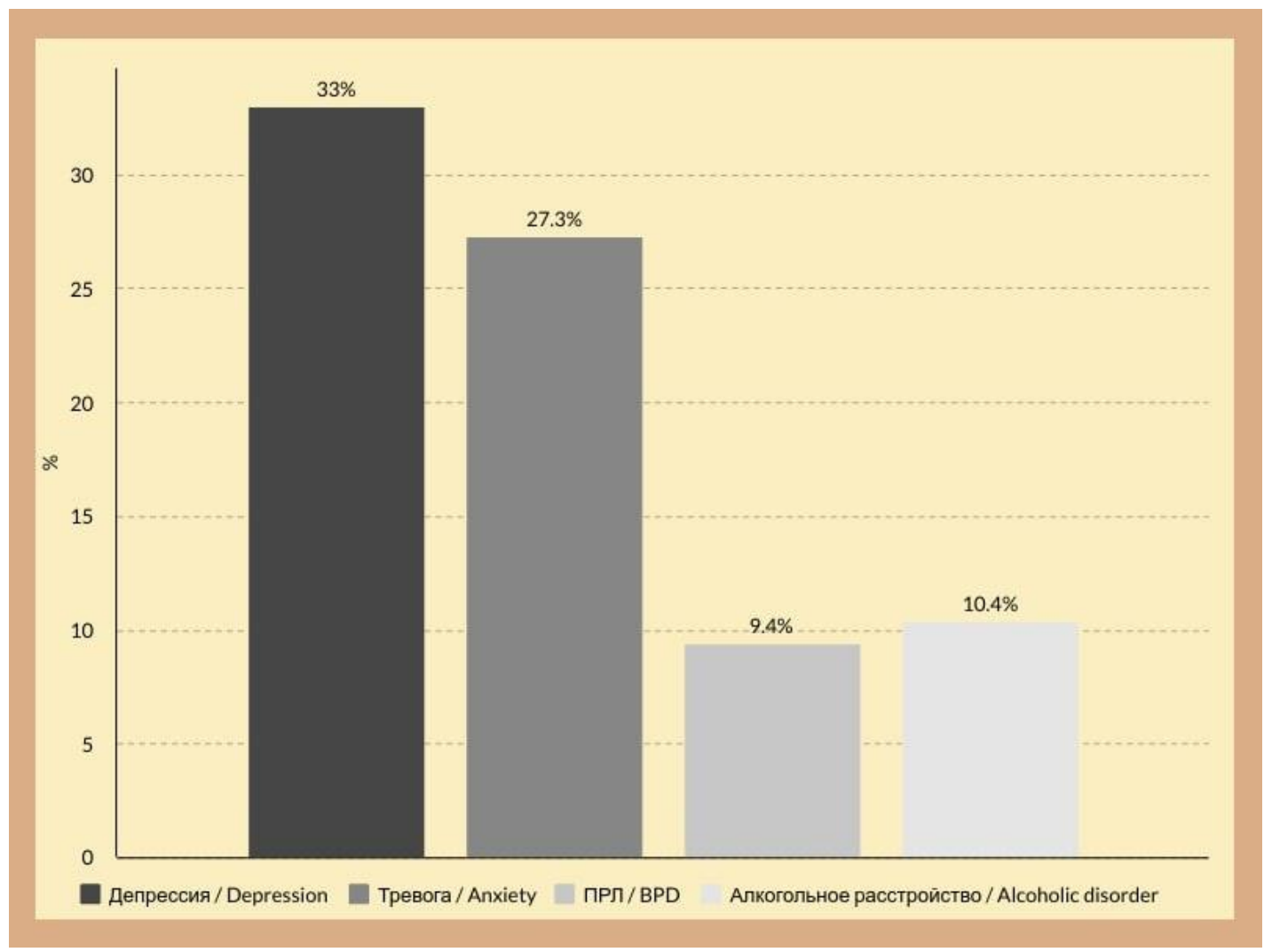

Puc. 2. Данные по психическому здоровью студентов высших учебных заведений Fig. 2. Mental health data for postsecondary students

В результате исследований социальная изоляция, связанная с ограничением на передвижения и социальным дистанцированием, была определена как ключевой фактор, который может привести к усилению проблем с психическим здоровьем. Следует 
отметить, что в своей выборке Хамза и коллеги [26] обнаружили: количество стрессоров (психологический термин, означающий внешний экстремальный фактор среды, вызывающий стресс), связанных с социальной изоляцией и одиночеством, значительно увеличилось, но только для тех, у кого ранее не было проблем с психическим здоровьем. Учащиеся с ранее существовавшими проблемами психического здоровья не сообщили об изменениях. Это открытие осветило новый аспект рассматриваемой проблемы, поскольку дало нам понять, что вопреки предположениям в этой области $[27,28]$, учащиеся, на которых усиление социального дистанцирования может наиболее неблагоприятно повлиять - это те, кто не привык чувствовать себя изолированными и одинокими. Иными словами, только учащиеся, которые испытывают растущую социальную изоляцию в результате COVID-19, могут подвергаться повышенному риску нарастания психологического стресса.

Кризис, вызванный пандемией, по-разному влияет на социальные отношения. Последние - это каналы социальной поддержки, которая в такие периоды важнее, чем когда-либо. При всех существующих возможностях виртуального общения физическая близость и возможность личного взаимодействия важны для развития и укрепления социальных связей [29]. Поскольку личное общение и встречи свелись к минимуму из-за мер социального дистанцирования, вполне вероятно, что люди сосредотачиваются на тех отношениях, которые являются пространственно близкими, наиболее значимыми или более устоявшимися. Отчасти их можно найти за пределами студенческого социума - в семье или в рамках уже существующего круга друзей. Однако внутри студенческого социума такие связи ослабевают, исчезают или не появляются вовсе - в последнем случае в отношении тех студентов, кто приступил к учёбе в 2020 г. Неполноценное участие в такой социальной группе, как студенчество, деформирует и замедляет процесс активного личностного развития. Как проявление ухудшения психического здоровья учащихся можно отметить депрессивные состояния, сниженную мотивацию к обучению, субъективное ощущение бесперспективности дальнейшего образования и неуверенность в последующей применимости полученной профессии.

Массовость таких явлений свидетельствует о необходимости активного поиска решений для минимизации последствий вынужденного социального дистанцирования и изоляции.

\section{Некоторые методы улучшения психического здоровья студентов}

Исследование проблем в этой области установило, что студенты-спортсмены, поддерживающие социальные связи с товарищами по команде во время пандемии, могут в большей степени сохранять свою спортивную идентичность и психическое здоровье [30]. Учащиеся, получавшие взаимную поддержку товарищей по команде, сообщали о хорошем психическом здоровье и благополучии.

Уникальные свойства групповой среды могут сделать принадлежность к ней особенно ценной для обеспечения благополучия и защиты от депрессии. Принимая во внимание, что активное членство в группах положительно влияет на показатели психического здоровья, сохранение его в периоды неблагоприятных условий часто требует, чтобы люди были обеспечены поддержкой тех самых социальных групп.

В ряде стран активную роль в сохранении ощущения принадлежности к такой группе, поддержании ослабленных социальных связей берут на себя студенческие сообщества. Студенческие союзы большинства университетов оказывают практическую поддержку учащимся, усиливают и увеличивают эффективность связи учащихся с административными органами вузов. Подобные объединения, возглавляемые студентами 
с высоким уровнем позитивной социальной активности, стараются привлечь прочих к участию в факультативных дистанционных мероприятиях, создают группы по интересам и таким образом переформатируют социальные связи, усиливают ощущение причастности студентов к своей социальной группе и активного участия в её жизни вообще и отдельных сегментов в частности. Вторичным результатом такой причастности становится желание обучающегося сохранить своё присутствие в студенческом социуме, что может быть обеспечено удовлетворительными результатами в учёбе, исключающими отчисление учащегося из вуза и, как следствие, потерю своего статуса.

Не стоит умалять и роль преподавателей вузов в поддержке студентов. Связь последних с вузом реализуется посредством взаимодействия с педагогами. При дистанционном образовании уровень удовлетворенности обучением также обусловлен качеством взаимодействия с преподавателями [31]. Сохранение уровня мотивации студента во многом зависит от правильного подбора и применения моделей повышения личностной мотивации, поддержки со стороны обучающих и влияет на степень оптимистического отношения к ближайшим перспективам. Оптимизм - важный показатель позитивного физического и психологического здоровья и может обеспечить выполнение защитной функции [32].

\section{Заключение}

Таким образом, для улучшения психического здоровья, сохранения высокой активности и формирования личности студентов требуется вырабатывание у последних стабильного ощущения причастности к студенчеству как социальной группе и несомненной идентификации себя как его составляющей.

Это может быть обеспечено за счёт создания активного коллектива, пусть на платформе виртуального общения, где более активные и психологически устойчивые члены оказывают регулярную поддержку нуждающимся в ней, инициируют различные мероприятия командного формата и образование групп по интересам, обеспечивающим их длительное стабильное существование.

Роль преподавателей не менее важна в подобных ситуациях, т. к. участие в учебном процессе, в отличие от любых студенческих объединений, - требование обязательное для всех обучающихся. Благодаря этому охватывается весь круг студентов, включая самых пассивных в плане социальных связей, а педагог получает возможность организации работы студентов и со студентами таким образом, что негативные аспекты обязательного дистанционного обучения компенсируются методиками обучения. К ним можно отнести групповое проектное обучение и командную работу, имеющую учебносоревновательный мотив.

В арсенал преподавателей, как было сказано выше, входит мотивация студентов, направленная на создание ощущения актуальности и применимости получаемого образования. Это позволит учащимся сохранить уверенность в необходимости обучения, обоснованности присутствия в вузе и участия в студенческом социуме.

Изложенные методы могут применяться не только в сегодняшней кризисной ситуации удалённого обучения, но и в перспективе, при создании эффективных курсов дистанционного образования.

\section{СПИСОК ЛИТЕРАТУРЫ}

1. Белянская Т.Э. Социально-психологические характеристики студенческого возраста // Ученые записки. Электронный журнал Курского государственного университета. - 2020. - № 3. URL https://cyberleninka.ru/article/n/sotsialno-psihologicheskie-harakteristiki-studencheskogo-vozrasta (дата обращения 26.02.2020). 
2. Епанчинцева Г.А., Козловская Т.Н. Студенчество как социально-психологическая общность // Вестник Оренбургского государственного университета. - 2018. - № 2. - С. 66-69.

3. Григорьева Е.А., Стоянов А.С. Осознанность и ожидания при выборе вуза и профессии // ГОСРЕГ: Государственное регулирование общественных отношений. - 2020. - № 2. - С. 256-267.

4. Большая зарплата или работа по специальности? // ВЦИОМ. URL: https://wciom.ru/analyticalreviews/analiticheskii-obzor/bolshaya-zarplata-ili-rabota-po-speczialnosti- (дата обращения 26.02.2020).

5. Туманова Д.И. Психолого-педагогические условия формирования сплоченности в студенческом коллективе // Научные исследования молодых ученых: Сборник статей Международной научнопрактической конференции. - Пенза: Наука и Просвещение, 2020. - C. 111-115.

6. Global overview reports. URL: https://datareportal.com/reports/?tag=Global+Overview (дата обращения 25.02.2020).

7. Pathological internet use - an important comorbidity in child and adolescent psychiatry: prevalence and correlation patterns in a naturalistic sample of adolescent inpatients / M. Fuchs, D. Riedl, A. Bock, G. Rumpold, K. Sevecke // BioMed Research International. - 2018. - V. 2018. URL: https://doi.org/10.1155/2018/1629147 (дата обращения 23.02.2020).

8. Прирост интернет-аудитории в 2019 году обеспечили пенсионеры // PБK. URL: https://www.rbc.ru/technology_and_media/13/01/2020/5e1876549a7947210b5ef636 (дата обращения 25.02.2020).

9. Студенты в период пандемии COVID-19: понимание ситуации самоизоляции / Е.А. Сорокоумова, Е.И. Чердымова, Е.Б. Пучкова, Л.В. Темнова // Научное обозрение. Серия 1 «Экономика и право». 2020. - № 3. - C. 196-205.

10. Digital 2021: Global overview report. URL: https://datareportal.com/reports/digital-2021-global-overviewreport (дата обращения 03.03.2020).

11. Trends in college students' mental health diagnoses and utilization of services, 2009-2015 / S.B. Oswalt, A.M. Lederer, K. Chestnut-Steich, C. Day, A. Halbritter, D. Ortiz // Journal of American College Health. 2020. - V. 68. - P. 41-51. URL: https://doi.org/10.1080/07448481.2018.1515748 (дата обращения 03.03.2020).

12. Undergraduate Student. Reference Group // American College Health Association. National College Health Assessment. 2019. URL: https://www.acha.org/documents/ncha/NCHA-III_FALL_2019_UNDERGRADUATE_REFERENCE_GROUP_DATA_REPORT.pdf (дата обращения 24.02.2020).

13. Lee J. Mental health effects of school closures during COVID-19 // The Lancet Child \& Adolescent Health. 2020. - V. 4. URL: https://doi.org/10.1016/S2352-4642(20)30109-7 (дата обращения 03.03.2020).

14. Statistics Canada. How are postsecondary students in Canada impacted by the COVID-19 pandemic? URL: https://www150.statcan.gc.ca/n1/pub/11-627-m/11-627-m2020032-eng.htm (дата обращения 03.03.2020).

15. Sahu P. Closure of universities due to coronavirus disease 2019 (COVID-19): Impact on education and mental health of students and academic staff // Cureus. - 2020. - V.12. - article e7541. URL: https://doi.org/10.7759/cureus.7541 (дата обращения 03.03.2020).

16. The psychological impact of the COVID-19 epidemic on college students in China / W. Cao, Z. Fang, G. Hou, M. Han, X. Xu, J. Dong, J. Zheng // Psychiatry Research. - 2020. - V. 287. - article 112934. URL: https://doi.org/10.1016/j.psychres.2020.112934 (дата обращения 03.03.2020).

17. Galea S., Merchant R.M., Lurie N. The mental health consequences of COVID-19 and physical distancing // Journal of the American Medical Association. - 2020. - V. 180. - P. 817-818. URL: https://doi.org/10.1002/da.20838 (дата обращения 03.03.2020).

18. Loneliness: a signature mental health concern in the era of COVID-19 / W.D.S. Killgore, S.A. Cloonan, E.C. Taylor, N.S. Dailey // Psychiatry Research. - 2020. - V. 290. - article 113117. URL: https://doi.org/10.1016/j.psychres.2020.113117 (дата обращения 03.03.2020).

19. Zhai Y., Du X. Addressing collegiate mental health amid COVID-19 pandemic // Psychiatry Research. 2020. - V. 288. - article 113003. URL: https://doi.org/10.1016/j.psychres.2020.113003 (дата обращения 03.03.2020).

20. Huang Y., Zhao N. Generalized anxiety disorder, depressive symptoms and sleep quality during COVID-19 outbreak in China: a web-based cross-sectional survey // Psychiatry Research. - 2020. - V. 288. - article 112954. URL: https://doi.org/10.1016/j.psychres.2020.112954 (дата обращения 03.03.2020).

21. Prevalence and predictors of PTSS during COVID-19 outbreak in China hardest-hit areas: Gender differences matter / N. Liu, F. Zhang, C. Wei, Y. Jia, Z. Shang, L. Sun, W. Liu // Psychiatry Research. - 2020. V. 287. - article 112921. URL: https://doi.org/10.1016/j.psychres.2020.112921 (дата обращения 03.03.2020).

22. A nationwide survey of psychological distress among Italian people during the COVID-19 pandemic: Immediate psychological responses and associated factors / C. Mazza, E. Ricci, S. Biondi, M. Colasanti, 
S. Ferracuti, C. Napoli, P. Roma // International Journal of Environmental Research and Public Health. 2020. - V. 17. - article 3165. URL: https://doi.org/10.3390/ijerph17093165 (дата обращения 03.03.2020).

23. A nationwide survey of psychological distress among Chinese people in the COVID-19 epidemic: Implications and policy recommendations / J. Qiu, B. Shen, M. Zhao, Z. Wang, B. Xie, Y. Xu // General Psychiatry. - 2020. - V. 33. - article e100213. URL: https://doi.org/10.1136/gpsych-2020-100213 (дата обращения 03.03.2020).

24. Statistics Canada. Mental health of Canadians during the COVID-19 pandemic. URL: https://www150.statcan.gc.ca/n1/en/pub/11-627-m/11-627-m2020039-eng.pdf?st=L8kMkZlk (дата обращения 03.03.2020).

25. Immediate psychological responses and associated factors during the initial stage of the 2019 coronavirus disease (COVID-19) epidemic among the general population in China / C. Wang, R. Pan, X. Wan, Y. Tan, L. Xu, C.S. Ho, R.C. Ho // International Journal of Environmental Research and Public Health. 2020. - V. 17. - article 1729. URL: https://doi.org/10.3390/ijerph17051729 (дата обращения 03.03.2020).

26. When social isolation is nothing new: a longitudinal study psychological distress during COVID-19 among university students with and without preexisting mental health concerns / C.A. Hamza, L. Ewing, N.L. Heath, A.L. Goldstein // Canadian Psychology/Psychologie canadienne. URL: http://dx.doi.org/10.1037/cap0000255 (дата обращения 03.03.2020).

27. Druss B.G. Addressing the COVID-19 pandemic in populations with serious mental illness // Journal of the American Medical Association Psychiatry. URL: https://doi.org/10.1001/jama.2020.3413 (дата обращения 03.03.2020).

28. Yao H., Chen J.H., Xu Y.F. Patients with mental health disorders in the COVID-19 epidemic // The Lancet Psychiatry. - 2020. - V. 7. - article e21. URL: https://doi.org/10.1016/S2215-0366(20)30090-0 (дата обращения 03.03.2020).

29. Short-term and long-term effects of a social network intervention on friendships among university students / Z. Boda, T. Elmer, A. Vörös, C. Stadtfeld // Scientific Reports. - 2020. - V. 10. - P .1-12. URL: https://www.nature.com/articles/s41598-020-59594-z (дата обращения 03.03.2020).

30. Social (Un)distancing: teammate interactions, athletic identity, and mental health of student-athletes during the COVID-19 pandemic / S. Graupensperger, A.J. Benson, J.R. Kilmer, M. Blair Evans // Journal of adolescent health. - 2020. - V. 67. - P. 662-670. URL: https://doi.org/10.1016/j.jadohealth.2020.08.001 (дата обращения 03.03.2020).

31. Соколовская И.Э. Социально-психологические факторы удовлетворенности студентов в условиях цифровизации обучения в период пандемии COVID-19 и самоизоляции // Цифровая социология. 2020. - T. 3. - № 2. - C. 46-54.

32. Федосеенко Е.В. Жизнь после карантина: психология смыслов и коронавирус COVID-19 // Психологические проблемы смысла жизни и акме: XXV международный симпозиум. - М.: Психологический институт РАO, 2020. - С. 34-47.

Поступила 10.03.2021 2. 


\title{
METHODS OF IMPROVEMENT OF STUDENTS MENTAL HEALTH IT THE TERMS OF FORCED DISTANCE LEARNING AND SOCIAL DISTANCING
}

\author{
Semen M. Levin, \\ levin.sm@asu.tusur.ru
}

\author{
Tomsk State University of Control Systems and Radioelectronics, \\ 40, Lenin avenue, Tomsk, 634050, Russia
}

Semen M. Levin, Cand. Sc., PhD, professor, Tomsk State University of Control Systems and Radioelectronics.

\begin{abstract}
Relevance. In the context of the COVID-19 pandemic, distance learning has become mandatory for numerous universities worldwide. The massive transfer to distance learning was unprecedented and unparalleled. The related need for isolation and social distancing influenced student groups' formation, the adaptation of students to a new social group - the student body. Higher education students faced additional new challenges, which led to increased mental health problems. Against the background of administrative restrictions and the impossibility of creating or maintaining traditional social ties due to the nature of the student society, the manifestation of anxiety, symptoms of depression, hard stress condition, and alcohol abuse facts became characteristic among students. It became necessary to identify the main symptoms of mental health disorders and their causes and methods and minimize such negative symptoms. This article also considers the format of personal communication between students as a necessary factor for full-fledged socialization and the formation of each student's personality. The study aims to comprehensively evaluate students' mental health disorders with the subsequent establishment of key channels of social support - active leaders of formal and informal student communities and teachers. The work results expressed in specific recommendations for improving students' mental health, with a targeted indication of the social ties they need to implement.
\end{abstract}

Key words: Students mental health concerns, distance learning, social distancing.

\section{REFERENCES}

1. Belyanskaya T.E. Sotsialno-psikhologicheskie kharakteristiki studentcheskogo vozrasta [Sociopsychological characteristics of student age]. Uchenyye zapiski. Elektronny zhurnal Kurskogo gosudarstvennogo universiteta, 2020, no. 3. Available at: https://cyberleninka.ru/article/n/sotsialnopsihologicheskie-harakteristiki-studencheskogo-vozrasta (accessed 26 February 2020).

2. Epachintseva G.A., Kozlovskaya T.N. Studenchestvo kak sotsialno-psikhologicheskaya obshchnost [Students as a socio-psychological community]. Vestnik Orenburgskogo gosudarstvennogo universiteta, 2018, no. 2, pp. 66-69.

3. Grigoreva E.A., Stoyanov A.S. Osoznannost i ozhidaniya pri vybore vuza i proffesii [Awareness and expectations when choosing a university and profession]. GOSREG: Gosudarstvennoe regulirovanie obshchestvennykh otnosheniy, 2020, no. 2, pp. 256-267.

4. Bolshaya zarplata ili rabota po spetsialnosti? [Big salary or work in your specialty?]. VZIOM. Available at: https://wciom.ru/analytical-reviews/analiticheskii-obzor/bolshaya-zarplata-ili-rabota-po-speczialnosti (accessed 26 February 2020).

5. Tumanova D.I. Psikhologo-pedagogicheskie usloviya formirovaniya splochennosti v studencheskom kollektive [Psychological and pedagogical conditions for the formation of cohesion in the student team]. Sbornik statey Mezhdunarodnoy nauchno-prakticheskoy konferentsii. Nauchnye issledovaniya molodykh uchenykh [Scientific research of young scientists: Collection of articles of the International scientific and practical conference]. Penza, Nauka i Prosveshchenie Publ., 2020. pp. 111-115.

6. Global overview reports. Available at: https://datareportal.com/reports/?tag=Global+Overview (accessed 25 February 2020). 
7. Fuchs M., Riedl D., Bock A., Rumpold G., Sevecke K. Pathological internet use - an important comorbidity in child and adolescent psychiatry: prevalence and correlation patterns in a naturalistic sample of adolescent inpatients. BioMed Research International, 2018, vol. 2018. Available at: https://doi.org/10.1155/ 2018/1629147 (accessed 23 February 2020).

8. Prirost internet-auditorii v 2019 godu obespechili pensionery [The increase in the Internet audience in 2019 provided by pensioners]. RBC. Available at: https://www.rbc.ru/technology_and_media/13/01/2020/ 5e1876549a7947210b5ef636 (accessed 25 February 2020).

9. Sorokoumova E.A., Chardimova E.I., Puchkova E.B., Temnova L.V. Studenty v period pandemii COVID19: ponimanie siuatsii samoizoliatsii [Students during the COVID 19 pandemic: understanding the situation of self-isolation]. Nauchnoe obozrenie. Seriya 1 «Ekonomika i pravo», 2020, no. 3, pp. 196-205.

10. Digital 2021: Global overview report. Available at: https://datareportal.com/reports/digital-2021-globaloverview-report (accessed 03 March 2021).

11. Oswalt S.B., Lederer A.M., Chestnut-Steich K., Day C., Halbritter A., Ortiz D. Trends in college students' mental health diagnoses and utilization of services, 2009-2015. Journal of American College Health, 2020, vol. 68, pp. 41-51. Available at: https://doi.org/10.1080/07448481.2018.1515748 (accessed 03 March 2021).

12. Undergraduate student. Reference group. American College Health Association. National College Health Assessment. 2019. Available at: https://www.acha.org/documents/ncha/NCHA-III_FALL_2019_ UNDERGRADUATE_REFERENCE_GROUP_DATA_REPORT.pdf (accessed 24 February 2020).

13. Lee J. Mental health effects of school closures during COVID-19. The Lancet Child \& Adolescent Health, 2020, vol. 4. Available at: https://doi.org/10.1016/S2352-4642(20)30109-7 (accessed 03 March 2021).

14. Statistics Canada. How are postsecondary students in Canada impacted by the COVID-19 pandemic? Available at: https://www150.statcan.gc.ca/n1/pub/11-627-m/11-627-m2020032-eng.htm (accessed 03 March 2021).

15. Sahu P. Closure of universities due to coronavirus disease 2019 (COVID-19): Impact on education and mental health of students and academic staff. Cureus, 2020, vol. 12, article e7541. Available at: https://doi.org/10.7759/cureus.7541 (accessed 03 March 2021).

16. Cao W., Fang Z., Hou G., Han M., Xu X., Dong J., Zheng J. The psychological impact of the COVID-19 epidemic on college students in China. Psychiatry Research, 2020, vol. 287, article 112934. Available at: https://doi.org/10.1016/j.psychres.2020.112934 (accessed 03 March 2021).

17. Galea S., Merchant R.M., Lurie N. The mental health consequences of COVID-19 and physical distancing. Journal of the American Medical Association, 2020, vol. 180, pp. 817-818. Available at: https://doi.org/10.1002/da.20838 (accessed 03 March 2021).

18. Killgore W.D.S., Cloonan S.A., Taylor E.C., Dailey N.S. Loneliness: A signature mental health concern in the era of COVID-19. Psychiatry Research, 2020, vol. 290, article 113117. Available at: https://doi.org/10.1016/j.psychres.2020.113117 (accessed 03 March 2021).

19. Zhai Y., Du X. Addressing collegiate mental health amid COVID-19 pandemic. Psychiatry Research, 2020 , vol. 288, article 113003. Available at: https://doi.org/10.1016/j.psychres.2020.113003 (accessed 03 March 2021).

20. Huang Y., Zhao N. Generalized anxiety disorder, depressive symptoms and sleep quality during COVID-19 outbreak in China: a web-based cross-sectional survey. Psychiatry Research, 2020, vol. 288, article 112954. Available at: https://doi.org/10.1016/j.psychres.2020.112954 (accessed 03 March 2021).

21. Liu N., Zhang F., Wei C., Jia Y., Shang Z., Sun L., Liu W. Prevalence and predictors of PTSS during COVID-19 outbreak in China hardest-hit areas: Gender differences matter. Psychiatry Research, 2020, vol. 287, article 112921. Available at: https://doi.org/10.1016/j.psychres.2020.112921 (accessed 03 March 2021).

22. Mazza C., Ricci E., Biondi S., Colasanti M., Ferracuti S., Napoli C., Roma P. A nationwide survey of psychological distress among Italian people during the COVID-19 pandemic: Immediate psychological responses and associated factors. International Journal of Environmental Research and Public Health, 2020, vol. 17, article 3165. Available at: https://doi.org/10.3390/ijerph17093165 (accessed 03 March 2021).

23. Qiu J., Shen B., Zhao M., Wang Z., Xie B., Xu Y. A nationwide survey of psychological distress among Chinese people in the COVID-19 epidemic: implications and policy recommendations. General Psychiatry, 2020, vol. 33, article e100213. Available at: https://doi.org/10.1136/gpsych-2020-100213 (accessed 03 March 2021)

24. Statistics Canada. Mental health of Canadians during the COVID-19 pandemic. Available at: https://www150.statcan.gc.ca/n1/en/pub/11-627-m/11-627-m2020039-eng.pdf?st=L8kMkZlk (accessed 03 March 2021). 
25. Wang C., Pan R., Wan X., Tan Y., Xu L., Ho C.S., Ho R.C. Immediate psychological responses and associated factors during the initial stage of the 2019 coronavirus disease (COVID-19) epidemic among the general population in China. International Journal of Environmental Research and Public Health, 2020, vol. 17, article 1729. Available at: https://doi.org/10.3390/ijerph17051729 (accessed 03 March 2021).

26. Hamza C.A., Ewing L., Heath N.L., Goldstein A.L. When social isolation is nothing new: a longitudinal study psychological distress during COVID-19 among university students with and without preexisting mental health concerns. Canadian Psychology/Psychologie canadienne. Available at: http://dx.doi.org/10.1037/cap0000255 (accessed 03 March 2021).

27. Druss B.G. Addressing the COVID-19 pandemic in populations with serious mental illness. Journal of the American Medical Association Psychiatry. Available at: https://doi.org/10.1001/jama.2020.3413 (accessed 03 March 2021).

28. Yao H., Chen J.H., Xu Y.F. Patients with mental health disorders in the COVID-19 epidemic. The Lancet Psychiatry, 2020, vol. 7, article e21. Available at: https://doi.org/10.1016/S2215-0366(20)30090-0 (accessed 03 March 2021).

29. Boda Z., Elmer T., Vörös A., Stadtfeld C. Short-term and long-term effects of a social network intervention on friendships among university students. Scientific Reports, 2020, vol. 10, P. 1-12. Available at: https://www.nature.com/articles/s41598-020-59594-z (accessed 03 March 2021).

30. Graupensperger S., Benson A.J., Kilmer J.R., Evans M.B. Social (Un)distancing: teammate interactions, athletic identity, and mental health of student-athletes during the COVID-19 pandemic. Journal of adolescent health, 2020, vol. 67, pp. 662-670. Available at: https://doi.org/10.1016/j.jadohealth.2020.08.001 (accessed 03 March 2021).

31. Sokolovskaya I.E. Sotsialno-psikhologicheskie factory udovletvorennosti studentov v usloviyakh tsifrovizatsii obucheniya v period pandemii COVID-19 i samoizoliatsii [Socio-psychological factors of student satisfaction in the context of digitalization of education during the COVID-19 pandemic and selfisolation]. Tsifrovaya sotsiologiya, 2020, vol. 3, no. 2, pp. 46-54.

32. Fedoseenko E.V. Zhizn posle karantina: psikhologia smyslov i koronavirus COVID-19 [Life after quarantine: psychology of meanings and the coronavirus COVID-19]. XXV mezhdunarodny simpozium. Psikhologicheskie problemy smysla zhizni i acme [XXV International Symposium. Psychological Problems of the Meaning of Life and Acme]. Moscow, Psikhologicheskiy institut RAO Publ., 2020. pp. 34-47.

Received: 03 March 2021. 